\title{
The Economic Analysis of the Behavior of Auditors
}

\author{
Cheng Huanling \\ Xi’An Internatianal University, Shaanxi China, 710077
}

Keywords: Behavior Auditors, Economic Analysis, Economic Trend

\begin{abstract}
This paper proposes three economic hypotheses from the three classic assumptions of economics: the hypothetical rational man hypothesis, the incompleteness of information, and the assumption that opportunistic behavior is assumed to be an economic analysis of the behavior of the auditors. At the end of this paper, a brief summary is made, and three policy recommendations are made on the audit behavior norms based on three economic assumptions.
\end{abstract}

\section{Introduction}

"Economic man" may be the most classic of classical economics a hypothesis. In Adam Smith, it is understood that people in the economic activities will be through the gains and losses and profit and loss of the precise calculation of the pursuit of their own interests to maximize. After the marginal revolution of economics in the 1870s, it was understood as the maximization of the marginal utility of man under certain constraints. In the tradition of neoclassical economics, the hypothesis of "economic man" is often closely related to the assumption of "reason", that is, economic rationality or rational economic man. The rational economic man can examine from two aspects, namely, rational consciousness and rational ability. Rationality refers to the desire of the economic man to pursue the maximization of his utility. One is the traditional neoclassical economics of "optimism" understanding that human beings are completely rational, that is, mankind is always with a keen eye to face everything can be thoughtful, the current and future possible choices and their results are well known, So that uncertainty and risk are gone. The other is Simon's limited view of reason, he believes that human rationality is subject to the environment in which the complexity and uncertainty, as well as human autonomic, physiological, language and other aspects of the restrictions, which is limited, Is not omnipotent, full and complete. The view of bounded rationality has been widely recognized by the economic community because it is more empirical.

The evaluation of the historical and cultural background, values, local customs and moral values of the evaluator, the value choice is often "bounded rational", and the evaluation made by this is relatively "accurate" and relatively "objective". Compared to the objective requirements of audit evaluation, "bounded rationality" poses a potential risk. At the same time, in the context of market economy and economic globalization, when we are surrounded by market utilitarian value, vulgar culture and the Western concept of free human rights, value orientation and value choice should attract high attention and vigilance. Although in most cases legitimacy and rationality are consistent. But in general, laws and regulations lag behind the development of practice, it is impossible to exhaust all economic and social phenomena, but also by the legislative experience and technical constraints. And therefore as one of the audit evaluation standards of laws and regulations have their inherent flaws. In actual work, audit evaluation sometimes has to fall into the dilemma of legitimacy and rationality. The risks in the application of laws and regulations are mainly manifested in the applicability and timeliness. Of course, the actual work there is still the audit discretion to understand, grasp and use the risk. 


\section{Limited Rational Economic Individual}

The auditor is first of all a rational economic individual. According to the above analysis, the auditor, as a rational economic individual, must also maximize his personal utility: Volume maximization; and second, the risk associated with future cash inflows is minimized. In fact, the auditors in this income and risk trade-offs in the corresponding audit "strategy" to achieve their utility to maximize. However, this trade-off between the auditors and the selection in the short term and long-term is significantly different, the following to be analyzed. We know that in a complete audit activity, there are three aspects of the relationship: all, managers, auditors. These three aspects of the relationship are pursuing their own interests. In the short term, the manager to maximize their own interests, he and the auditors "conspiracy" to jointly deal with everyone is a rational choice, the auditors can not prepare the financial statements prepared by the administrator to seriously review, or even fully Trust to minimize audit costs. Of course, the auditors should also consider the risk of matching with the future is the smallest. In the short term, as long as the manager and the auditors together, all short-term will not understand too much, he will trust the auditors. So the short-term risk of auditors will not be too big. This is only in the short term a "game" case, the manager and the auditors together "cheating" success. And in the long-term repeated "game", the situation is different. The auditor is unable to cooperate with the manager for "conspiracy" to deal with everyone with the trust of all. Thus, it is particularly desirable for all auditors to perform audits that will reduce the risk of negligence and achieve acceptable levels. It is also important to consider the reputation of the audit firm and the auditor, and the different auditing firms have different reputations, and the reputation of the audit firm is positively related to the quality of the audit work itself. The users of the financial statements, that is, the owners of the audit relationship framework, are highly trustworthy in the audit reports provided by the high quality audit services and are willing to pay higher than the audit fees of the general audit firm. Thus, for auditors, there is a long-term incentive mechanism to improve the quality of the audit work, to maintain their own independence, and thus dedicated to all services.

\section{Incomplete Information and Asymmetric Distribution of Assumptions}

In the three relationships among the auditors, the information about the managerial ability and the working effort of the business manager is asymmetric about the relationship between the owner and the manager. The shareholders of the enterprise do not know, and the enterprise the operator is very clear that it is private information. In the case of the agent relationship between the auditor and the auditor, the information about the audit quality of the auditor and the degree of the audit effort is asymmetric, and the shareholders of the enterprise do not know, and the auditor knows that it is private information. If person information is complete, there is no information asymmetric distribution of information, and incomplete information may be symmetrical distribution, that you and I understand each other's understanding of the information, and understand each other do not understand what information. In this sense, the information asymmetric distribution assumes that the information is incomplete. In the traditional neoclassical economics, people are completely rational, so as to grasp the complexity and uncertainty of the environment, the information is complete and symmetrical distribution, and then the market must be fully competitive and balanced. Thus, the incomplete and asymmetric distribution of information is precisely the logical extension of this basic assumption that the rational man is boundless rationality. Incomplete information and asymmetric distribution is an important assumption based on the study of modern economics. If the information is complete, it is also symmetrical distribution, then the cost of the transaction will be zero, the externalities of human behavior will be all internalized, people can not ride, incentive and restraint problems no longer exist, natural accounting is also unnecessary. And thus based on the accounting based on the audit will lose the meaning of existence. The reason why the fraud has been the root of the existence of this fraud is that all the people, managers, auditors of the information between the asymmetry. 


\section{People's Opportunistic Behavioral Tendencies and Auditors' Behavior}

Opportunistic behavior can be divided into pre-opportunistic behavior and post-opportunistic behavior. Prior opportunistic behavior refers to opportunistic behavior that the parties to the transaction use to sign asymmetry before using the contract. Prior opportunistic behavior is usually discussed in the "reverse selection model" of information economics. And post-opportunism refers to the parties involved in the transaction after the use of information asymmetry and opportunistic behavior. Such ex post opportunistic behavior is often referred to as "moral hazard" or "moral behavior".

From the three parties of the audit relationship - the owner, the manager, the auditor, the parties are faced with the difficult truth to reveal the problem, and the degree of opportunism is not exactly the same. For auditors, opportunism is embodied in two orientations of accounting standards preferences: one tendency is that in the event of future uncertainties, auditors tend to choose strict accounting standards and avoid distorting economic conditions. Such as R \& D costs or capitalization issues, when the accounting standards require immediate costs, the auditors can not worry about the friction between the customer and the dispute, do not have to fear to lose customers, because the rigidity of the guidelines, other auditors are also the same criteria must be adopted. Another tendency is that when there are a variety of alternative approaches to accounting policies under accounting standards, auditors will take full advantage of the flexibility of such accounting standards and tend to choose to include both rigorous calculation procedures and flexibility Reporting guidelines. Such as accounting on FIFo and LIFO and other historical cost-based inventory options to reflect the rigorous calculation of the unity of the program and flexibility. These potential inventory options implicitly allow auditors to agree with customers to avoid losing customers. In short, the auditors will make full use of accounting standards "rigid" and "flexibility", combined with their own acceptable audit risk, the use of loose accounting standards play a role in the buffer; the use of strict accounting policy, you can provide A convenient shelter.

\section{Conclusion}

There is a kind of opportunistic tendency in the face of this kind of "reality", and we have the following suggestions:

The behavior of the auditors should be regulated and bound by the limited rationality of the auditors. From the legal norms, the establishment of a sound independent audit of the professional norms system, to minimize the legal and regulatory loopholes; from the system construction, nurture and develop an independent fair audit market, prohibit administrative intervention, promote accounting firms and other intermediaries market In order to separate the consulting and auditing business of the accounting firm from the organization design, the promotion of the accounting firm's partnership and limited partnership system, the auditor's honor and the rise and fall of the accounting firm "tied together" together.

In the framework of the principal-agent relationship of the audit, it is necessary to strengthen the supervision and restriction of the owner to the auditor (the trustee) and reduce the information asymmetry in the audit. To give the auditor or the accounting firm the right to be effectively given to the owner, fundamentally change the choice of many listed companies in the accounting firm is actually controlled by the management of the situation. It is recommended that the final appointment and veto right of the accounting firm be chosen by the shareholders' meeting in the listed company, or the board of directors of the listed company shall be promoted by the board of directors. This system shall enjoy the right of independent director system effectively fulfill their rights.

In order to reduce the opportunist tendencies in the auditing process, it is necessary to establish a high quality accounting system and reduce the number of alternative methods existing in the existing standards, and try to reduce the auditors' To strengthen the capital market signal transmission mechanism and the reputation of the audit market mechanism, the implementation of listed companies accounting firm's regular rotation system to limit the accounting firm and the 
audited units of the "conspiracy" behavior.

\section{References}

[1] Liang Shuxiang. Economic Analysis of Government's Audit of Corrupt Behavior[J]. Journal of Auditing Monthly. 2006 (12)

[2] Yang Huijun, Yang Weiguo. Scientific approach to audit behavior[J]. Journal of Wuhan University of Technology (Information \& Management Engineering Edition). 2005 (04)

[3] Zhang Jianjun, Lin Zhiwei. Audit market game - Chinese independent audit behavior alienation analysis[J]. Journal of Shenzhen University (Humanities and Social Sciences) .2005 (06)

[4] Liu Xiaonian, Yueyang. Behavioral audit research: review and enlightenment [J]. Audit Research. 2005 (02)

[5] Shao Jiangxia. Analysis of the behavior of audit work[J]. Productivity Research. 2004 (01)

[6] Zhu Wenming. Economic Behavior Hypothesis Analysis of Auditor Behavior[J]. China Certified Public Accountant. 2004 (04) 